\title{
Inequalities in Awareness and Attitude towards HPV and Its Vaccine between Local and Migrant Residents Who Participated in Cervical Cancer Screening in Shenzhen, China
}

Wei Lin, MS'
Yueyun Wang, MD
Zhihua Liu, MD²
Bin Chen, MS
Shixin Yuan, MS ${ }^{1}$
Bo Wu, MS
Lin Gong, $\mathrm{BS}^{1}$

Departments of ${ }^{1}$ Healthcare and ${ }^{2}$ Gynaecology, Affiliated Shenzhen Maternity and Child Healthcare Hospital, Southern Medical University, Shenzhen, China

Correspondence: Yueyun Wang, MD Department of Healthcare, Affiliated Shenzhen Maternity and Child Healthcare Hospital, Southern Medical University, No. 3012 Fuqiang Road, Futian District, Shenzhen 518048, China Tel: 86-075582889999

Fax: 86-075582889999

E-mail: wangyueyun@126.com

Co-correspondence: Zhihua Liu, MD Department of Gynecology, Affiliated Shenzhen Maternity and Child Healthcare Hospital, Southern Medical University, No. 2004 Hongli Road, Futian District, Shenzhen 518028, China Tel: 86-075582889999

Fax: 86-075582889999

E-mail: drzhliu@163.com

Received January 24, 2019

Accepted June 28, 2019

Published Online July 1, 2019

\begin{abstract}
Purpose
A cross-sectional survey was conducted to evaluate the differences on awareness and attitude towards human papillomavirus (HPV) and its vaccine between local and migrant residents who participated in cervical cancer screening in Shenzhen, China.
\end{abstract}

\section{Materials and Methods}

A total of 9,855 females sampled from healthcare institutions in 20 street blocks through the Cervical Cancer Prevention Network were surveyed in this study by a self-administered questionnaire. Multivariate logistic regression was conducted to explore the role of the hukou and resident status in the willingness to receive HPV vaccination.

\section{Results}

Local residents had a relatively higher awareness of HPV (62.0\% vs. $35.6 \%$ vs. $29.9 \%$, $p<$ 0.001 ) and its vaccine ( $35.3 \%$ vs. $15.4 \%$ vs. $14.8 \%, p<0.001)$, as well as a higher willingness to receive HPV vaccination $(68.5 \%$ vs. $62.5 \%$ vs. $56.2 \%, p<0.001)$ than non-permanent residents and floating population. Except for age, education level, marital status, monthly income, having daughter(s), and heard of HPV and its vaccine, the hukou and resident status significantly associated with the willingness to receive HPV vaccination (local residents vs. floating population: odds ratio, 1.216; 95\% confidence interval, 1.057 to 1.398). None significant difference on the associated factors was found between local residents and internal migrants ( $p$ for interactions $>0.05$ ).

\section{Conclusion}

Inequalities in awareness and attitude towards HPV and its vaccine existed between local and migrant residents in Shenzhen. The hukou and resident status did impact on the willingness to receive HPV vaccination, therefore, it is critical to implement effective health education campaigns on HPV and its vaccine among internal migrants.

\section{Introduction}

Cervical cancer is the fourth most frequently detected cancer among females, with estimated data of 569,847 new cases and 311,365 deaths in 2018 worldwide [1]. It is well established that human papillomavirus (HPV) is one of the most common sexually transmitted pathogens in the genital system, and persistent infection with high-risk HPV genotypes is the major cause of cervical cancer [2]. When calculated by

\section{Key words}

Human papillomavirus, Vaccines, Awareness, Attitude, Internal migrants 
China is one of the largest developing country, which has been estimated with 98,900 new cases and 30,500 deaths annually according to nationwide cancer statistics by the National Cancer Center in 2015 [7]. However, these data likely underestimate the true disease burden of cervical cancer, since imparity exists in the opportunity of cervical cancer screening for women with various demographic and geographic factors throughout the country [8]. Furthermore, many rural women may fail to get HPV vaccination and cervical screening tests due to poverty, inadequate health service resources, and lack of knowledge [9]. It is widely accepted that health disparities are greatly affected by sociodemographic factors, such as housing, living, and work environment, health and social care services, education and unemployment and welfare [10], which closely relate to household registration status in China [11].

Hukou, a household registration status of Chinese, divides people into two sub-groups, which are local residents and internal migrants. Internal migrants in China usually refer to those who do not change their official hukou registration to the new location which they move to (i.e., floating population or non-permanent residents) [12]. China has a large number of internal migrants (almost 244.5 million in 2017) according to the 2018 Report on China's Migrant Population Development (http://www.nhfpc.gov.cn/zhuz/xwfb / 201812/ a32a43b225a740c4bff8f2168b0e9688.shtml). Shenzhen, as one of the economically developed cities in China, has approximately $65 \%$ of the population were internal migrants, reaching nearly 8.2 million by the end of 2017 according to the Shenzhen Statistical Yearbook, 2018 (http://tj.sz.gov.cn/ xxgk/zfxxgkml/tjsj/tjnj/201812/t20181229_14966437.htm). Researchers in Shenzhen find that the quality of primary health care given to migrants is less satisfactory than that provided to local residents [13]. Possible explanations found by previous studies are internal migrants have poorer sociodemographic characteristics than their local counterparts, such as lack of health insurance, which result in poor quality of health care received and the following unsatisfactory health outcome [14].

The successful implementation and high uptake of the HPV vaccine depend on people's knowledge of HPV infection, and the awareness of the effect of HPV vaccination on cervical cancer prevention [15]. Previous surveys on the awareness of HPV and attitudes towards the HPV vaccine have been conducted for various populations in China [16-18]. However, little attention has been given to people with different hukou statuses. Whether female migrants have accordant awareness and attitude towards HPV and its vaccine with local residents still remains uncertain. As HPV vaccines (Cervarix, Gardasil, and Gardasil 9) have been introduced in China only for a short time period, studies on females' attitude toward HPV vaccination are also essential to measure the effect of previous health education and also help the decision-making process of HPV vaccine promotion. In this study, we conducted a cross-sectional survey, and attempted to evaluate the awareness of HPV and the HPV vaccine, as well as the willingness to HPV vaccination among females local and migrant residents who participated in cervical cancer screening in Shenzhen, China. We further explored the factors associated with the willingness of HPV vaccination, in order to provide clues for the application of HPV vaccination among females with different hukou statuses in China.

\section{Materials and Methods}

\section{Study population}

This survey on the attitude towards HPV and the HPV vaccine was conducted between January and June 2015 in 20 street blocks from all administrative districts of Shenzhen city, with a multistage, stratified cluster sampling method to obtain the present sample. First, we selected two street blocks from each administrative district by simple randomization. Second, the list of all healthcare institutions which could provide cervical cancer screening services in the selected street block was collected through the Cervical Cancer Prevention Network of Shenzhen city for convenience by existed contacts. Third, we divided these healthcare institutions into two categories based on the workload of cervical cancer screening in 2014, including category A (screening less than 500 women) and B (screening more than 500 women). Subsequently one representative healthcare institution from each category was selected by simple randomization. Lastly, women aged from 21 to 60 years old, living in the selected regions, without a history of HPV vaccination, volunteered to join the study were recruited when they received cervical cancer screening service in the healthcare institutions. The overall response rate was $93.86 \%$. According to the hukou status, women recruited in the survey were grouped into two categories: local residents (residents with a hukou of Shenzhen city) and internal migrants (women living in Shenzhen but without a hukou of Shenzhen city). Besides, internal migrants were further divided into two groups based on their staying time in Shenzhen: non-permanent residents (women had stayed in Shenzhen for equal and more than six months), and floating population (women had stayed in Shenzhen for less than six months), consistent with the definition in The Administrative Measures for Population Statistics and Monitor published by the Shenzhen City Government (http://www.sz.gov.cn/ zfgb/2006/gb517/200810/t20081019_94738.htm). 


\section{Data collection}

The questionnaire used in the survey was modified and adapted from those used in Chinese populations based on published papers and expert opinions $[16,17]$ and was written in Mandarin Chinese in simple and clear language. It consisted of questions about sociodemographic characteristics, knowledge of HPV and the HPV vaccine, the willingness to vaccinate themselves and their daughter(s) with the HPV vaccine, the reasons against willingness to be vaccinated, and the acceptance of self-paying for HPV vaccination. Awareness of HPV was assessed using the question "Before today, had you heard of HPV?" Women who answered "yes" to this question were considered to be aware of HPV. Awareness of HPV vaccine was assessed in the same way. These questions have been previously reported in other studies in China $[17,18]$. Some specific questions were also used to estimate women's knowledge for HPV and its vaccine preliminarily, such as "Is HPV infection a sexually transmitted infection?," "Can persistent infection of high-risk HPV lead to cervical cancer?," "Can HPV vaccine prevent cervical cancer?", and "Should HPV vaccination be received before the first sexual intercourse?" As previous studies did [19], the acceptance of HPV vaccination was assessed by asking "Are you willing to receive HPV vaccination for yourself?" and "Are you willing to receive HPV vaccination for your daughter? (only for women with daughter)." Some questions had three possible options (Yes/No/Don't know), while the option “Don't know" was considered an incorrect answer. Females who signed the informed consent completed the questionnaire with the help of trained research investigators. Survey data were double entered in a database developed by using EpiData (EpiData Association, Odense, Denmark).

\section{Statistical analysis}

Data were analyzed using SPSS ver. 20.0 (IBM Corp., Armonk, NY). The demographic characteristics of participants, awareness of HPV and the HPV vaccine, and willingness to be vaccinated were presented by frequencies and percentages. The chi-square test was used to analyze the difference between local residents and internal migrants. Logistic regression model was used to analyze the association of potential associated variables with the willingness of HPV vaccination. Variables in the univariate analysis were entered into a multivariate logistic regression model, in which adjusted odds ratio (OR) and 95\% confidence intervals (95\% CI) were calculated. Stratified analysis was applied to detect whether the associated factors with the willingness of HPV vaccination were modified by the hukou status. We tested for multiplicative interactions by including the product term in multivariate logistic regression models. Statistical signifi- cance was assessed by two-tailed tests with a level of 0.05 .

\section{Ethical statement}

The study was approved by the Ethical Review Committee of Affiliated Shenzhen Maternity and Child Healthcare Hospital (No. 2013-004), Southern Medical University. Study objectives and questionnaire matters were explained to parents before the survey. Informed consent was obtained from each participant prior to our survey.

\section{Results}

\section{Demographic characteristics of all participants}

A total of 9,855 females were included in the final analysis. Demographic characteristics of the study subjects were presented in Table 1. The mean age of these women was 37.09 years old (standard deviation, 7.48). Among them, 92\% women were ethnic Han Chinese. The proportions of local residents, non-permanent residents, and floating population were $28.4 \%, 58.1 \%$, and $13.6 \%$, respectively. Forty-seven point two percent of women had not been educated higher than the junior middle school. The majority of them were married $(90.6 \%)$ and only having one sexual partner in the past six months $(92.5 \%)$. Twenty-three point two percent of them did not have a medical insurance and $14.4 \%$ of them had a low monthly income (less than 2,000 RMB). The percentages of women with an older age at menarche ( $\geq 12$ years old) and at the first sexual intercourse ( $\geq 18$ years old) were $89.0 \%$ and $93.5 \%$, respectively. More than half of the participants $(58.8 \%)$ had one or more daughters. All above demographic characteristics differently distributed in three groups according to hukou and resident status (all p < 0.05).

\section{Awareness and attitude of HPV and the HPV vaccine among females with different residence statuses in Shen- zhen}

As shown in Table 2, of females who responded to concerning questions, $42.3 \%$ had heard of HPV, and only $21.0 \%$ had heard of the HPV vaccine. When stratified by hukou and resident status, local residents had a relatively higher awareness of HPV (62.0\% vs. $35.6 \%$ vs. $29.9 \%, \mathrm{p}<0.001)$ and the HPV vaccine ( $35.3 \%$ vs. $15.4 \%$ vs. $14.8 \%, \mathrm{p}<0.001$ ) than nonpermanent residents and floating population.

Among who had heard of HPV, $71.0 \%$ of them knew that HPV infection is a sexually transmitted infection, and $55.1 \%$ of them knew that the persistent infection of high-risk HPV 
Table 1. Demographic characteristics of all participants

\begin{tabular}{|c|c|c|c|c|c|}
\hline Variable & $\begin{array}{c}\text { Total } \\
(\mathrm{n}=9,855)\end{array}$ & $\begin{array}{l}\text { Local residents } \\
\qquad(\mathrm{n}=2,796)\end{array}$ & $\begin{array}{l}\text { Non-permanent } \\
\text { residents }(n=5,721)\end{array}$ & $\begin{array}{l}\text { Floating population } \\
\qquad(n=1,338)\end{array}$ & p-value \\
\hline \multicolumn{6}{|l|}{ Age (yr) } \\
\hline$<30$ & $1,207(12.2)$ & $158(5.7)$ & 793 (13.9) & $256(19.1)$ & $<0.001$ \\
\hline $30-39$ & $5,234(53.1)$ & $1,504(53.8)$ & $3,110(54.4)$ & $620(46.3)$ & \\
\hline$\geq 40$ & $3,414(34.6)$ & $1,134(40.6)$ & $1,818(31.8)$ & $462(34.5)$ & \\
\hline \multicolumn{6}{|l|}{ Race } \\
\hline Han & $9,319(92.7)$ & 2,727 (97.5) & $5,376(94.0)$ & $1,036(77.4)$ & $<0.001$ \\
\hline Other & $716(7.3)$ & $69(2.5)$ & $345(6.0)$ & $302(22.6)$ & \\
\hline \multicolumn{6}{|l|}{ Education } \\
\hline Junior school or below & $4,648(47.2)$ & $496(17.7)$ & $3,304(57.8)$ & $848(63.4)$ & $<0.001$ \\
\hline High school & $2,544(25.8)$ & $728(26.0)$ & $1,529(26.7)$ & $287(21.4)$ & \\
\hline College graduate or above & $2,510(25.5)$ & $1,560(55.8)$ & 851 (14.9) & $99(7.4)$ & \\
\hline Unknown & $153(1.6)$ & $12(0.4)$ & $37(0.6)$ & $104(7.8)$ & \\
\hline \multicolumn{6}{|l|}{ Marital status } \\
\hline Married & $8,933(90.6)$ & $2,544(91.0)$ & $5,272(92.2)$ & $1,117(83.5)$ & $<0.001$ \\
\hline Single/Divorced/Widowed & $922(9.4)$ & $252(9.0)$ & $449(7.8)$ & $221(16.5)$ & \\
\hline \multicolumn{6}{|l|}{ Medical insurance } \\
\hline No insurance & $2,288(23.2)$ & $303(10.8)$ & $1,590(27.8)$ & $395(29.5)$ & $<0.001$ \\
\hline Urban medical insurance & $3,951(40.1)$ & $1,798(64.3)$ & $1,874(32.8)$ & $279(20.9)$ & \\
\hline Rural medical insurance & $1,294(13.1)$ & $222(7.9)$ & $833(14.6)$ & $239(17.9)$ & \\
\hline Commercial insurance or others & $2,322(23.6)$ & $473(16.9)$ & $1,424(24.9)$ & $425(31.8)$ & \\
\hline \multicolumn{6}{|l|}{ Monthly income (RMB) } \\
\hline$<2,000$ & $1,415(14.4)$ & $283(10.1)$ & $858(15.0)$ & $274(20.5)$ & $<0.001$ \\
\hline $2,000-3,999$ & $2,989(30.3)$ & $405(14.5)$ & $2,079(36.3)$ & $505(37.7)$ & \\
\hline $4,000-5,999$ & $2,232(22.6)$ & $577(20.6)$ & $1,419(24.8)$ & $236(17.6)$ & \\
\hline $6,000-9,999$ & $1,571(15.9)$ & $659(23.6)$ & $809(14.1)$ & $103(7.7)$ & \\
\hline$\geq 10,000$ & $1,236(12.5)$ & $776(27.8)$ & $399(7.0)$ & $61(4.6)$ & \\
\hline Unknown & $412(4.2)$ & $96(3.4)$ & $157(2.7)$ & 159 (11.9) & \\
\hline \multicolumn{6}{|l|}{ Age at menarche (yr) } \\
\hline$<12$ & $980(9.9)$ & $369(13.2)$ & $510(8.9)$ & $101(7.5)$ & $<0.001$ \\
\hline$\geq 12$ & $8,768(89.0)$ & $2,395(85.7)$ & $5,147(90.0)$ & $1,226(91.6)$ & \\
\hline Unknown & $107(1.1)$ & $32(1.1)$ & $64(1.1)$ & $11(0.8)$ & \\
\hline \multicolumn{6}{|l|}{ Age at sex debut (yr) } \\
\hline$<18$ & $223(2.3)$ & $33(1.2)$ & $124(2.2)$ & $66(4.9)$ & $<0.001$ \\
\hline$\geq 18$ & $9,214(93.5)$ & $2,632(94.1)$ & $5,380(94.0)$ & $1,202(89.8)$ & \\
\hline Unknown & $418(4.2)$ & $131(4.7)$ & $217(3.8)$ & $70(5.2)$ & \\
\hline \multicolumn{6}{|l|}{$\begin{array}{l}\text { No. of the sexual partners } \\
\text { in the past } 6 \text { months }\end{array}$} \\
\hline 1 & $9,115(92.5)$ & $2,599(93.0)$ & $5,331(93.2)$ & $1,185(88.6)$ & 0.008 \\
\hline$\geq 2$ & $441(4.5)$ & $105(3.8)$ & $259(4.5)$ & $77(5.8)$ & \\
\hline Unknown & $299(3.0)$ & $92(3.3)$ & $131(2.3)$ & $76(5.7)$ & \\
\hline \multicolumn{6}{|l|}{ Having daughter(s) } \\
\hline No & $3,847(39.0)$ & $1,193(42.7)$ & $2,147(37.5)$ & 507 (37.9) & $<0.001$ \\
\hline Yes & $5,799(58.8)$ & $1,560(55.8)$ & $3,454(60.4)$ & $785(58.7)$ & \\
\hline Unknown & $209(2.1)$ & $43(1.5)$ & $120(2.1)$ & $46(3.4)$ & \\
\hline
\end{tabular}

Values are presented as number $(\%)$. The chi-square test was used and $\mathrm{p}<0.05$ was considered as statistically significant. 
Table 2. Awareness and attitude of HPV and the HPV vaccine among females with different hukou and residence statuses

\begin{tabular}{|c|c|c|c|c|c|}
\hline Items & $\begin{array}{c}\text { Total } \\
(\mathrm{n}=9,855)\end{array}$ & $\begin{array}{l}\text { Local residents } \\
\qquad(\mathrm{n}=2,796)\end{array}$ & $\begin{array}{l}\text { Non-permanent } \\
\text { residents }(n=5,721)\end{array}$ & $\begin{array}{l}\text { Floating population } \\
\qquad(\mathrm{n}=1,338)\end{array}$ & p-value \\
\hline \multicolumn{6}{|l|}{ Heard of HPV } \\
\hline Yes & $4,169(42.3)$ & $1,733(62.0)$ & $2,036(35.6)$ & $400(29.9)$ & $<0.001$ \\
\hline No & $5,686(57.7)$ & $1,063(38.0)$ & $3,685(64.4)$ & $938(70.1)$ & \\
\hline \multicolumn{6}{|l|}{$\begin{array}{l}\text { Know that HPV infection is } \\
\text { a sexually transmitted infection }{ }^{\text {a) }}\end{array}$} \\
\hline Yes & $2,958(71.0)$ & $1,373(79.2)$ & $1,360(66.8)$ & $225(56.2)$ & $<0.001$ \\
\hline No & $1,211(29.0)$ & $360(20.8)$ & $676(33.2)$ & $175(43.8)$ & \\
\hline \multicolumn{6}{|c|}{$\begin{array}{l}\text { Know that the persistent infection of } \\
\left.\text { high-risk HPV could lead to cervical cancer }{ }^{2}\right)\end{array}$} \\
\hline Yes & $2,296(55.1)$ & $1,135(65.5)$ & $996(48.9)$ & 165 (41.2) & $<0.001$ \\
\hline No & $1,873(44.9)$ & $598(34.5)$ & $1,040(51.1)$ & $235(58.8)$ & \\
\hline \multicolumn{6}{|l|}{ Heard of the HPV vaccine } \\
\hline Yes & $2,065(21.0)$ & $986(35.3)$ & $881(15.4)$ & $198(14.8)$ & $<0.001$ \\
\hline No & $7,790(79.0)$ & $1,810(64.7)$ & $4,840(84.6)$ & $1,140(85.2)$ & \\
\hline \multicolumn{6}{|l|}{$\begin{array}{l}\text { Know that the HPV vaccine can } \\
\text { prevent cervical cancer }{ }^{\text {b) }}\end{array}$} \\
\hline Yes & $1,188(57.5)$ & $648(65.7)$ & $451(51.2)$ & $89(44.9)$ & $<0.001$ \\
\hline No & $877(42.5)$ & $338(34.3)$ & $430(48.8)$ & $109(55.1)$ & \\
\hline \multicolumn{6}{|c|}{$\begin{array}{l}\text { Know that HPV vaccination should be } \\
\text { received before the first sexual intercourse }{ }^{\text {b) }}\end{array}$} \\
\hline Yes & $524(25.4)$ & $293(29.7)$ & $196(22.2)$ & $35(17.7)$ & $<0.001$ \\
\hline No & $1,541(74.6)$ & $693(70.3)$ & $685(77.8)$ & $163(82.3)$ & \\
\hline \multicolumn{6}{|l|}{ Willing to vaccinate themselves } \\
\hline Yes & $6,241(63.3)$ & $1,916(68.5)$ & $3,573(62.5)$ & $752(56.2)$ & $<0.001$ \\
\hline No & $3,614(36.7)$ & $880(31.5)$ & $2,148(37.5)$ & $586(43.8)$ & \\
\hline \multicolumn{6}{|l|}{ Willing to vaccinate their daughter(s) ${ }^{c}$} \\
\hline Yes & $4,284(73.9)$ & $1,170(75.0)$ & $2,551(73.9)$ & $563(71.7)$ & 0.233 \\
\hline No & $1,515(26.1)$ & $390(25.0)$ & $903(26.1)$ & $222(28.3)$ & \\
\hline \multicolumn{6}{|l|}{$\begin{array}{l}\text { The reasons for unwilling to take } \\
\text { the HPV vaccine }\end{array}$} \\
\hline Worry about the safety & $1,419(39.3)$ & $384(43.6)$ & $838(39.0)$ & $197(33.6)$ & $<0.001$ \\
\hline $\begin{array}{l}\text { The HPV vaccine has not been } \\
\text { widely accepted }\end{array}$ & $727(20.1)$ & $219(24.9)$ & $409(19.0)$ & 99 (16.9) & \\
\hline Worry about the price & $361(10.0)$ & $40(4.5)$ & 255 (11.9) & $66(11.3)$ & \\
\hline Worry about the effectiveness & $301(8.3)$ & $55(6.2)$ & $193(9.0)$ & $53(9.0)$ & \\
\hline $\begin{array}{l}\text { Not considering themselves at risk } \\
\text { of cervical cancer }\end{array}$ & $229(6.3)$ & $31(3.5)$ & $154(7.2)$ & $44(7.5)$ & \\
\hline $\begin{array}{l}\text { The vaccine isn't protective because } \\
\text { they have sexual intercourse }\end{array}$ & $118(3.3)$ & $23(2.6)$ & $59(2.7)$ & $36(6.1)$ & \\
\hline Other reasons & $459(12.7)$ & $128(14.5)$ & $240(11.2)$ & $91(15.5)$ & \\
\hline \multicolumn{6}{|l|}{$\begin{array}{l}\text { Accept that they pay for the HPV } \\
\text { vaccination by themselves }{ }^{\text {e) }}\end{array}$} \\
\hline Yes & $1,870(30.0)$ & $796(41.5)$ & $878(24.6)$ & $196(26.1)$ & $<0.001$ \\
\hline No & $4,371(70.0)$ & $1,120(58.5)$ & $2,695(75.4)$ & $556(73.9)$ & \\
\hline
\end{tabular}

Values are presented as number $(\%)$. The chi-square test was used and $\mathrm{p}<0.05$ was considered as statistically significant.

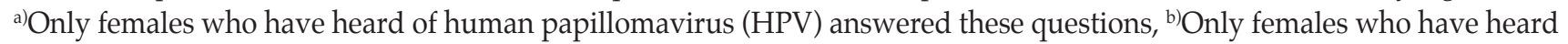
of the HPV vaccine answered these questions, c)Only females who have daughter(s) answered the question, d)Only females

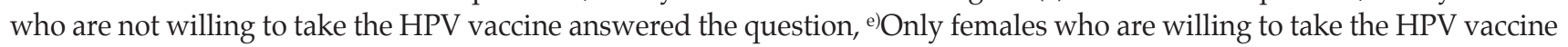
answered the question. 
Table 3. Factors associated with the willingness to receive HPV vaccination among females

\begin{tabular}{|c|c|c|}
\hline \multirow{2}{*}{ Variable } & \multicolumn{2}{|c|}{ Willingness to receive HPV vaccination $(n=9,855)$} \\
\hline & OR $(95 \% \mathrm{CI})$ & aOR $(95 \% \mathrm{CI})$ \\
\hline \multicolumn{3}{|l|}{ Age (yr) } \\
\hline$\geq 40$ & 1.000 (reference) & 1.000 (reference) \\
\hline $30-39$ & $1.342(1.228-1.211)$ & $1.248(1.127-1.381)$ \\
\hline$<30$ & $1.059(0.926-1.211)$ & $1.109(0.951-1.294)$ \\
\hline \multicolumn{3}{|l|}{ Race } \\
\hline Other & 1.000 (reference) & 1.000 (reference) \\
\hline Han & $1.183(1.013-1.382)$ & $0.960(0.796-1.159)$ \\
\hline \multicolumn{3}{|l|}{ Hukou and resident status } \\
\hline Floating population & 1.000 (reference) & 1.000 (reference) \\
\hline Non-permanent residents & $1.296(1.149-1.462)$ & $1.134(0.954-1.349)$ \\
\hline Local residents & $1.697(1.483-1.941)$ & $1.216(1.057-1.398)$ \\
\hline \multicolumn{3}{|l|}{ Education } \\
\hline Junior school or below & 1.000 (reference) & 1.000 (reference) \\
\hline High school & $1.374(1.243-1.519)$ & $1.204(1.074-1.350)$ \\
\hline College graduate or above & $1.907(1.717-2.118)$ & $1.353(1.168-1.566)$ \\
\hline \multicolumn{3}{|l|}{ Marital status } \\
\hline Single/Divorced/Widowed & 1.000 (reference) & 1.000 (reference) \\
\hline Married & $1.317(1.148-1.512)$ & $1.212(1.021-1.438)$ \\
\hline \multicolumn{3}{|l|}{ Medical insurance } \\
\hline No insurance & 1.000 (reference) & 1.000 (reference) \\
\hline Urban medical insurance & $1.263(1.135-1.405)$ & $1.015(0.898-1.148)$ \\
\hline Rural medical insurance & $0.931(0.810-1.070)$ & $1.001(0.862-1.164)$ \\
\hline Commercial insurance or others & $1.063(0.943-1.197)$ & $1.014(0.888-1.158)$ \\
\hline \multicolumn{3}{|l|}{ Monthly income (RMB) } \\
\hline$<2,000$ & 1.000 (reference) & 1.000 (reference) \\
\hline $2,000-3,999$ & $1.033(0.909-1.175)$ & $0.964(0.838-1.109)$ \\
\hline $4,000-5,999$ & $1.264(1.103-1.449)$ & $1.024(0.881-1.191)$ \\
\hline $6,000-9,999$ & $1.437(1.238-1.668)$ & $1.037(0.875-1.229)$ \\
\hline$\geq 10,000$ & $1.959(1.662-2.310)$ & $1.261(1.039-1.531)$ \\
\hline \multicolumn{3}{|l|}{ Age at menarche (yr) } \\
\hline$<12$ & 1.000 (reference) & 1.000 (reference) \\
\hline$\geq 12$ & $0.840(0.730-0.966)$ & $0.921(0.791-1.073)$ \\
\hline \multicolumn{3}{|l|}{ Age at sex debut (yr) } \\
\hline$<18$ & 1.000 (reference) & 1.000 (reference) \\
\hline$\geq 18$ & $1.509(1.156-1.970)$ & $1.198(0.888-1.617)$ \\
\hline \multicolumn{3}{|c|}{ No. of the sexual partners in the past 6 mo } \\
\hline 1 & 1.000 (reference) & 1.000 (reference) \\
\hline$\geq 2$ & $1.144(0.935-1.401)$ & $1.192(0.958-1.484)$ \\
\hline \multicolumn{3}{|l|}{ Having daughter(s) } \\
\hline No & 1.000 (reference) & 1.000 (reference) \\
\hline Yes & $1.315(1.208-1.431)$ & $1.355(1.236-1.487)$ \\
\hline \multicolumn{3}{|l|}{ Heard of HPV } \\
\hline No & 1.000 (reference) & 1.000 (reference) \\
\hline Yes & $1.818(1.670-1.980)$ & $1.431(1.292-1.584)$ \\
\hline \multicolumn{3}{|l|}{ Heard of the HPV vaccine } \\
\hline No & 1.000 (reference) & 1.000 (reference) \\
\hline Yes & $1.964(1.760-2.190)$ & $1.470(1.293-1.670)$ \\
\hline
\end{tabular}

Variables in univariate logistic regression models eventually entered the multivariable logistic regression model. HPV, human papillomavirus; OR, odds ratio; aOR, adjusted odds ratio; $\mathrm{CI}$, confidence interval. 


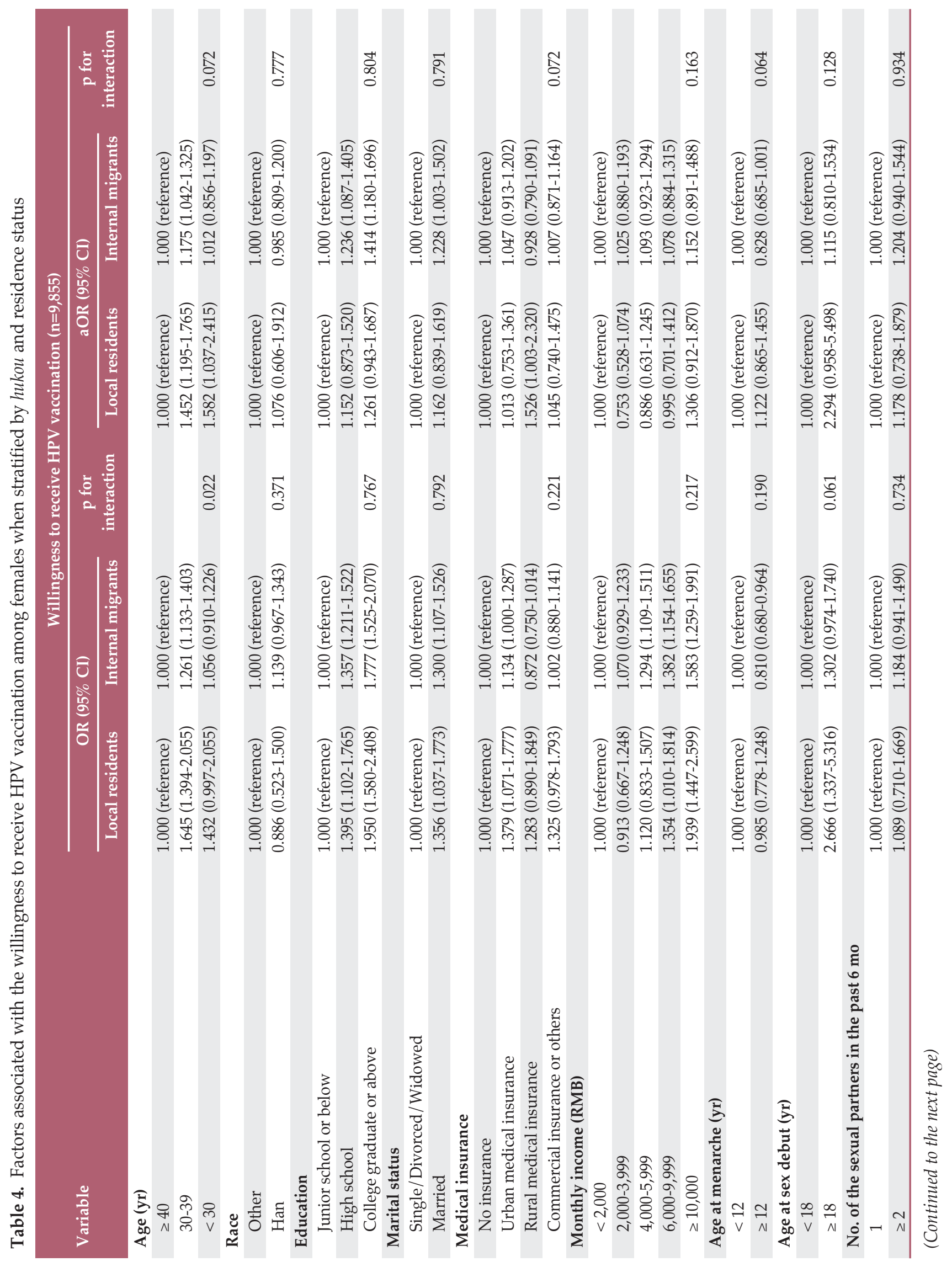




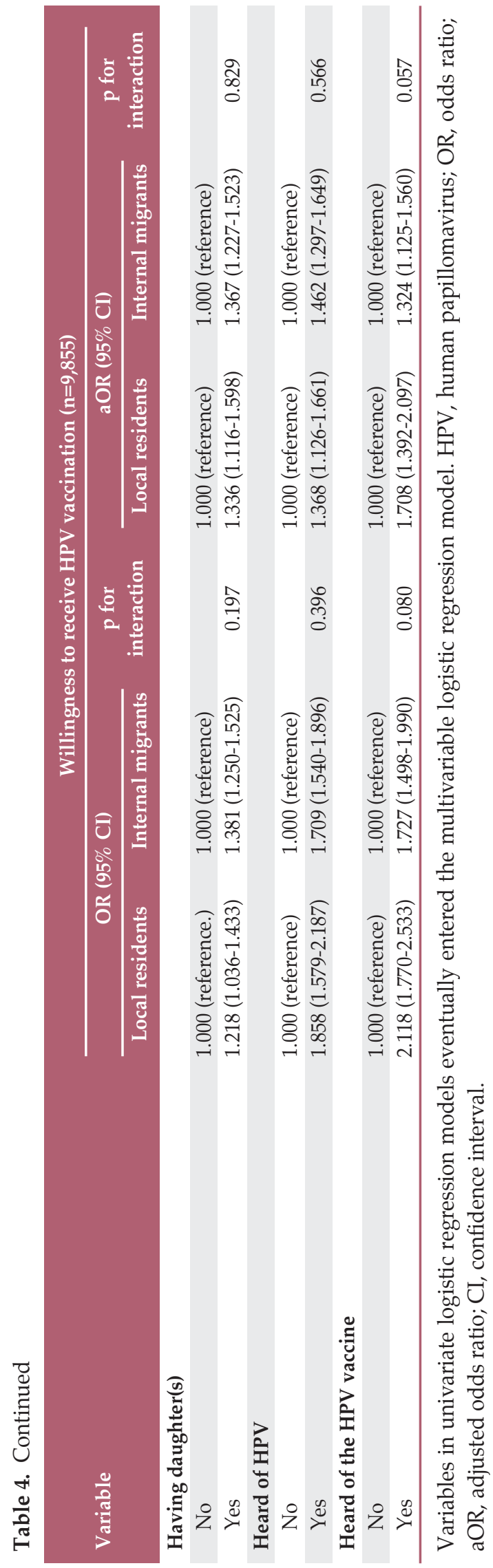

could lead to cervical cancer. Meanwhile, among who had heard of the HPV vaccine, $57.5 \%$ of them knew that the HPV vaccine can prevent cervical cancer, however, only $25.4 \%$ of them knew that HPV vaccination should be received before the first sexual intercourse. When compared to non-permanent residents and floating population, local residents had a higher awareness for all the questions referred to HPV and the HPV vaccine $(p<0.001)$.

Totally $63.3 \%$ of the participants were willing to take the HPV vaccine. Similarly, local residents had a higher willingness than non-permanent residents and floating population ( $68.5 \%$ vs. $62.5 \%$ vs. $56.2 \%, p<0.001)$. Seventy-three point nine percent of whom had one or more daughters were willing to vaccinate their daughters; however, the willingness to vaccinate their daughter(s) were not varied among females by the hukou and resident status. Among those who were willing to take the HPV vaccine, the acceptance to pay for the HPV vaccination by themselves was also higher in local residents ( $41.5 \%$ vs. $24.6 \%$ vs. $26.1 \%, \mathrm{p}<0.001)$. In addition, the main reasons for the unwillingness of HPV vaccination were worrying the safety of the vaccine $(39.3 \%)$, HPV vaccination not being widely accepted $(20.1 \%)$, worrying the price $(10.0 \%)$ and the effectiveness of vaccine $(8.3 \%)$, not considering themselves at risk of cervical cancer (6.3\%), and thinking no effect of vaccination because they had sexual intercourse before $(3.3 \%)$, with a proportion of $12.7 \%$ for other unknown reasons.

\section{Factors associated with the willingness to receive HPV vaccination among females in Shenzhen}

The factors associated with the willingness to receive HPV vaccination among females were presented in Table 3. A high willingness was associated with younger ages at 30-39 years old (OR, 1.248; 95\% CI, 1.127 to 1.381), being local residents (OR, 1.216; 95\% CI, 1.057 to 1.398), higher levels of education (OR, 1.204; 95\% CI, 1.074 to 1.350 for high school; OR, 1.353; 95\% CI, 1.168 to 1.566 for college graduate or above), being married (OR, 1.212; 95\% CI, 1.021 to 1.438), high monthly income $\geq 10,000$ RMB (OR, 1.261; 95\% CI, 1.039 to 1.531 ), having daughter(s) (OR, 1.355; 95\% CI, 1.236 to 1.487), heard of HPV (OR, 1.431; 95\% CI, 1.292 to 1.584), and heard of HPV vaccine (OR, 1.470; 95\% CI, 1.293 to 1.670). When stratified by the $h u k o u$ and residence status, we did not find significant difference on the associated factors between local residents and internal migrants, all $\mathrm{p}$ for interactions were $>0.05$ (Table 4). 


\section{Discussion}

Migrants were recognized as a particularly vulnerable population for the reason that they did not have the same rights to benefit from social security and welfare as the local permanent residents [20]. To our knowledge, it is the first study to compare females' awareness and attitude towards HPV and its vaccine between local and migrant residents in China, which could provide novel clues to cervical cancer prevention among internal migrants. We found local residents had the best awareness of HPV and its vaccine, followed by non-permanent residents and floating population. Similar findings were observed for the willingness of HPV vaccination.

There were several large sample surveys on HPV awareness among females in China, which reported the proportions of women who had heard of HPV ranged from $15.0 \%-44.9 \%[16,17,19,21]$. We observed a higher proportion of $62.0 \%$ among local residents, followed by $35.6 \%$ among non-permanent residents and $29.9 \%$ among floating population. When compared with data from developed countries, only local residents in Shenzhen had consistent awareness of $\mathrm{HPV}$, since the proportion of heard of HPV were $87.7 \%$, $61.6 \%$, and $71.8 \%$ in the United States, United Kingdom, and Australia, respectively [22], indicating that women in richer regions might know more about HPV. Additionally, the proportion of heard of HPV vaccine was previously reported about $17.4 \%$ (95\% CI, $13.06 \%$ to $22.20 \%$ ) in Chinese female population from a meta-analysis of 58 observational studies [23]. Here we similarly observed a higher proportion among local residents $(35.3 \%)$ except for non-permanent residents $(15.4 \%)$ and floating population (14.8\%). However, females' awareness of HPV vaccine was still far away from those in economically developed countries [22], in which a government-mediated program for HPV vaccination was established as WHO recommended. The potential association between socioeconomic characteristics and awareness of HPV and its vaccine required further studies, since populations in published surveys demonstrated a range of cultural, ethnic, socioeconomic and other differences.

Women' willingness to vaccinate themselves differed by hukou and residence statues, while the proportions of willingness to vaccinate their daughter(s) among non-permanent residents and floating population were in accord with that among local residents. Data showed that the acceptability was nearly or over $80 \%$ among Chinese general female population from several large sample surveys [16,17,19], which reflected a lower acceptability for HPV vaccination in Shenzhen. The major concerns against HPV vaccination varied between local residents and internal migrants. Both worries about the safety of the vaccine and considering HPV vacci- nation not being widely accepted affected local residents more than internal migrants. However, internal migrants paid more attention to the price and the effectiveness of HPV vaccine, as well as their self-perception risk of cervical cancer. Furthermore, poorer economic status might play an essential role in women's acceptability for HPV vaccination, as the willingness to pay for vaccination was relatively lower in internal migrants in our survey, which might correlate with the fact that most of them had low-income level.

In our study, internal migrants showed a poor knowledge of HPV and its vaccine, and a lower acceptability to HPV vaccination than their local counterparts. Perhaps reasons for these inequalities were their disparity on sociodemographic characteristics. We found that internal migrants were more likely to be younger, non-Han minority, low-educated, lowincome, single, lack of health insurance, and earlier to be engaged in sexual activity, which gave evidence of their vulnerable living situations as other reported articles suggested [24-26]. However, we did not observe that the associated factors of the willingness to receive HPV vaccination varied between local residents and internal migrants. Despite of hukou and resident status, having daughter(s) and heard of HPV and its vaccine did increase the acceptability to HPV vaccination both for local residents and internal migrants. It was conventionally thought that parental factors involved in HPV vaccine acceptability for the children [27]. Possible explanations might be that mothers would pay more attention to HPV vaccination if they had daughter(s), leading to a higher awareness of HPV and its vaccine, which did help to improve the intention to vaccinate both themselves and their daughter(s). Compliance with previous studies [28-30], we found that women who had heard of HPV and its vaccine were more likely to accept it, emphasizing that insufficient knowledge about the vaccine might become another important attitudinal barrier to the uptake of vaccine among females.

Some limitations should be addressed. First, representative healthcare institutions that provided cervical cancer screening services were selected as the survey sites, in which both local residents and internal migrants shared the same opportunity to receive screening services. Although our findings cannot be generalized to the entire female population in Shenzhen, the study subjects could be a representative sample of women who participated in cervical cancer screening. In consideration of relative better health belief among screening women, the awareness and attitude towards HPV and its vaccine among Shenzhen females may be overestimated, further large sample population-based surveys are in demand. Second, our study focused on acceptability rather than uptake of the HPV vaccine, in a sample where HPV awareness was relatively low; therefore, it is unclear whether women' intentions to be vaccinated would translate into 
behavior. Third, some of women may not have fully understood the questions due to different education levels, resulting in potential bias. Nevertheless, we provided assistance from trained research investigators if they required help. Fourth, we did not use a standard scale for Knowledge-Attitude/Belief-Practice (KAP model) to evaluate women's HPV related knowledge and perceptions of HPV vaccination, which might impact on the accuracy and completeness of information collection. Because of the limited explorations in developing HPV KAP scale, Chinese scholars usually adopted self-draft questionnaires based on expert opinions and previous reports [16-19]. The present questionnaire we used was modified from published articles. As the assessment for the awareness and attitude of HPV and its vaccine based on individual items was consistent with previous studies, the validity should be guaranteed to a certain extent. Moreover, although this survey was conducted in 2015, the time before the introduction of HPV vaccines into mainland China, and the results might not reflect the present perception of HPV / HPV vaccine among Chinese women. Nevertheless, our findings could indicate background levels of women's awareness and attitude towards HPV and its vaccine. Further perspective studies are demanded to address the improvement of HPV knowledge after vaccine permission in China.

In conclusion, our study detected inequalities in awareness and attitude towards HPV and its vaccine between local and migrant residents who participated in cervical cancer screen- ing in Shenzhen, which provide novel insights to find out key obstacles for the potential uptake of HPV vaccination. Except for age, education level, marital status, monthly income, having daughter(s), and heard of HPV and its vaccine, the hukou and resident status did impact on the willingness to receive HPV vaccination. Therefore, it is critical to implement effective health education campaigns to raise awareness and knowledge of HPV and its vaccine among internal migrants.

\section{Conflicts of Interest}

Conflict of interest relevant to this article was not reported.

\section{Acknowledgments}

We thank all participants involved in this survey and medical professionals who helped to complete the survey questionnaires. Special thanks to Dr. Youlin Qiao and Dr. Fanghui Zhao from the Cancer Institute of Chinese Academy of Medical Science (CICAMS) for providing expertise in the development of the study.

This study was funded by Sanming Project of Medicine in Shenzhen (SZSM201612042) and Shenzhen Healthcare Research Project (SZXJ2017011 and SZGW2018005). The funder did not participate in any part of the study from design to approval of the manuscript, except for supporting this project.

\section{References}

1. Bray F, Ferlay J, Soerjomataram I, Siegel RL, Torre LA, Jemal A. Global cancer statistics 2018: GLOBOCAN estimates of incidence and mortality worldwide for 36 cancers in 185 countries. CA Cancer J Clin. 2018;68:394-424.

2. Schiffman M, Castle PE, Jeronimo J, Rodriguez AC, Wacholder S. Human papillomavirus and cervical cancer. Lancet. 2007; 370:890-907.

3. de Martel C, Plummer M, Vignat J, Franceschi S. Worldwide burden of cancer attributable to HPV by site, country and HPV type. Int J Cancer. 2017;141:664-670.

4. World Health Organization. Comprehensive cervical cancer control: a guide to essential practice. 2nd ed. Geneva: World Health Organization; 2014.

5. Lim JN, Ojo AA. Barriers to utilisation of cervical cancer screening in Sub Sahara Africa: a systematic review. Eur J Cancer Care (Engl). 2017;26:e12444.

6. Fisher WA, Laniado H, Shoval H, Hakim M, Bornstein J. Barriers to human papillomavirus vaccine acceptability in Israel. Vaccine. 2013;31 Suppl 8:I53-7.

7. Chen $\mathrm{W}$, Zheng R, Baade PD, Zhang S, Zeng H, Bray F, et al.
Cancer statistics in China, 2015. CA Cancer J Clin. 2016;66:11532.

8. Wang B, He M, Chao A, Engelgau MM, Saraiya M, Wang L, et al. Cervical cancer screening among adult women in China, 2010. Oncologist. 2015;20:627-34.

9. Liu T, Li S, Ratcliffe J, Chen G. Assessing knowledge and attitudes towards cervical cancer screening among rural women in eastern China. Int J Environ Res Public Health. 2017;14:E967.

10. Bambra C, Gibson M, Sowden A, Wright K, Whitehead M, Petticrew M. Tackling the wider social determinants of health and health inequalities: evidence from systematic reviews. J Epidemiol Community Health. 2010;64:284-91.

11. Chen J. Internal migration and health: re-examining the healthy migrant phenomenon in China. Soc Sci Med. 2011;72: 1294-301.

12. Goodkind D, West LA. China's floating population: definitions, data and recent findings. Urban Stud. 2002;39:2237-50.

13. Li H, Chung RY, Wei X, Mou J, Wong SY, Wong MC, et al. Comparison of perceived quality amongst migrant and local patients using primary health care delivered by community 
health centres in Shenzhen, China. BMC Fam Pract. 2014;15:76.

14. Yuan B, Qian X, Thomsen S. Disadvantaged populations in maternal health in China who and why? Glob Health Action. 2013;6:19542.

15. Kessels SJ, Marshall HS, Watson M, Braunack-Mayer AJ, Reuzel R, Tooher RL. Factors associated with HPV vaccine uptake in teenage girls: a systematic review. Vaccine. 2012;30: 3546-56.

16. Zhao FH, Tiggelaar SM, Hu SY, Zhao N, Hong Y, Niyazi M, et al. A multi-center survey of HPV knowledge and attitudes toward HPV vaccination among women, government officials, and medical personnel in China. Asian Pac J Cancer Prev. 2012;13:2369-78

17. Li J, Li LK, Ma JF, Wei LH, Niyazi M, Li CQ, et al. Knowledge and attitudes about human papillomavirus (HPV) and HPV vaccines among women living in metropolitan and rural regions of China. Vaccine. 2009;27:1210-5.

18. Zhang SK, Pan XF, Wang SM, Yang CX, Gao XH, Wang ZZ, et al. Perceptions and acceptability of HPV vaccination among parents of young adolescents: a multicenter national survey in China. Vaccine. 2013;31:3244-9.

19. Chen L, Song Y, Ruan G, Zhang Q, Lin F, Zhang J, et al. Knowledge and attitudes regarding HPV and vaccination among Chinese women aged 20 to 35 years in Fujian Province: a cross-sectional study. Cancer Control. 2018;25:1073274818775356.

20. Gong X, Luo X, Ling L. Prevalence and associated factors of secondhand smoke exposure among internal Chinese migrant women of reproductive age: evidence from China's LaborForce Dynamic Survey. Int J Environ Res Public Health. 2016; 13:371.

21. He J, He L. Knowledge of HPV and acceptability of HPV vac- cine among women in western China: a cross-sectional survey. BMC Womens Health. 2018;18:130.

22. Marlow LA, Zimet GD, McCaffery KJ, Ostini R, Waller J. Knowledge of human papillomavirus (HPV) and HPV vaccination: an international comparison. Vaccine. 2013;31:763-9.

23. Zhang Y, Wang Y, Liu L, Fan Y, Liu Z, Wang Y, et al. Awareness and knowledge about human papillomavirus vaccination and its acceptance in China: a meta-analysis of 58 observational studies. BMC Public Health. 2016;16:216.

24. Derose KP, Escarce JJ, Lurie N. Immigrants and health care: sources of vulnerability. Health Aff (Millwood). 2007;26:125868.

25. Weiyuan C. China's new health plan targets vulnerable. Bull World Health Organ. 2010;88:5-6.

26. Gu H, You H, Ning W, Zhou H, Wang J, Lu Y, et al. Internal migration and maternal health service utilisation in Jiangsu, China. Trop Med Int Health. 2017;22:124-132.

27. Nan X, Zhao X, Briones R. Parental cancer beliefs and trust in health information from medical authorities as predictors of HPV vaccine acceptability. J Health Commun. 2014;19:100-14.

28. Oh JK, Jeong BY, Yun EH, Lim MK. Awareness of and attitudes toward human papillomavirus vaccination among adults in Korea: 9-year changes in nationwide surveys. Cancer Res Treat. 2018;50:436-444.

29. Arrossi S, Maceira V, Paolino M, Sankaranarayanan R. Acceptability and uptake of HPV vaccine in Argentina before its inclusion in the immunization program: a population-based survey. Vaccine. 2012;30:2467-74.

30. Mouallif M, Bowyer HL, Festali S, Albert A, Filali-Zegzouti Y, Guenin S, et al. Cervical cancer and HPV: awareness and vaccine acceptability among parents in Morocco. Vaccine. 2014;32: 409-16. 